\title{
Facile Preparation of Nitrogen-doped Porous Carbons via Salt Melt Synthesis with Efficient Catalytic Desulfurization Performance
}

\author{
YU Zheng-Fa, WANG Xu-Zhen, HOU Ya-Nan, ZHAO Zong-Bin, Rui Li, QIU Jie-Shan
}

\begin{abstract}
(State Key Lab of Fine Chemicals, Key Lab for Energy Materials and Chemical Engineering of Liaoning Province, School of Chemistry, Faculty of Chemical, Environmental and Biological Science and Technology Engineering, Dalian University of Technology, Dalian 116024, China)
\end{abstract}

\begin{abstract}
A series of N-doped porous carbons were prepared using biomass D-glucose and nitrogen-rich melamine as precursors via facile salt melt synthesis method. The obtained N-doped porous carbons exhibit developed porosity (BET surface area up to $1355 \mathrm{~m}^{2} / \mathrm{g}$ ) and notablely high nitrogen content $(20.73 \mathrm{wt} \%)$. X-ray photoelectron spectroscope (XPS) results indicate that the nitrogen configurations in the carbons are mainly pyrrolic and pyridinic functional groups, which are in favor of catalytic oxidation of hydrogen sulfide to elemental sulfur. High sulfur capacity of $1.10 \mathrm{~g} / \mathrm{g}$ is achieved over the optimized carbon materials at room temperature and ambient pressure, showing the excellent adsorptive-catalytic performance of $\mathrm{N}$-doped porous carbons for hydrogen sulfide removal. The facile synthesis route enables a great potential for the scale-preparation of N-doped porous carbons and application in pollution control.
\end{abstract}

Key words: nitrogen-doped porous carbon; salt melt synthesis; hydrogen sulfide; metal free catalytic oxidation

Hydrogen sulfide $\left(\mathrm{H}_{2} \mathrm{~S}\right)$ always exists in natural gas, biogas, syngas, and flue gas. Industrial gas containing $\mathrm{H}_{2} \mathrm{~S}$ has big bad effects on the industry process including poisoning catalysts and corroding engines ${ }^{[1]}$. Among the various methods for $\mathrm{H}_{2} \mathrm{~S}$ removal, such as wet scrubbing ${ }^{[2]}$, Clause process ${ }^{[3]}$, biological method ${ }^{[4]}$ and catalytic oxidation processes ${ }^{[5]}$, direct oxidation of $\mathrm{H}_{2} \mathrm{~S}$ to elemental sulfur shows great potential ${ }^{[6]}$. Porous carbons have been demonstrated to be one of the most suitable candidates for $\mathrm{H}_{2} \mathrm{~S}$ removal due to their developed porosity and tunable surface chemistry. For example, impregnation with caustic agents $\left(\mathrm{NaOH}\right.$ or $\mathrm{Na}_{2} \mathrm{CO}_{3}$ ) would result in high concentration of $\mathrm{HS}^{-}$ions by promoting $\mathrm{H}_{2} \mathrm{~S}$ dissociating in the presence of moisture, leading to enhanced catalytic activity and reaction kinetics $^{[7-8]}$. Unfortunately, chemical modifications of porous carbons are additional steps in carbon manufacturing, which bring about the high cost of the adsorbent and make the adsorbent corrosive. In addition, ignition temperatures of the modified carbons are lowered by the exothermic reaction taking place on the carbon surface ${ }^{[7]}$.

Alternatively, nitrogen doped porous carbons (NPCs) can be used as highly efficient and metal-free catalysts for direct oxidation of $\mathrm{H}_{2} \mathrm{~S}$ to elemental sulfur ${ }^{[6,9-11]}$. Nitrogen doping level is of great importance for the catalytic activity because nitrogen content in NPCs determines HS $^{-}$concentration derived from $\mathrm{H}_{2} \mathrm{~S}$ dissociating, which are sub- sequently oxidized by chemisorbed oxygen ${ }^{[6,9-11]}$. As a consequence, NPCs with high nitrogen doping level are highly desirable for catalytic oxidation of $\mathrm{H}_{2} \mathrm{~S}$ to elemental sulfur. Recently, salt melt synthesis method, which shows many advantages, has been explored for preparing various nanocarbon materials ${ }^{[12-14]}$. On one hand, the salts can act as excellent solvents at wide temperature range that solvothermal processes cannot reach. On the other hand, the porogen can be isolated from the products easily just by washing with water due to their high solubility in water. Therefore, this synthesis approach is scalable and environmental benign due to the salt cyclicity ${ }^{[13]}$.

In this study, we present the successful synthesis of high nitrogen-doped porous carbons using melamine and D-glucose as precursors via a facile salt melt route. Owing to the notably high nitrogen content and developed porosity, the porous carbons exhibit high-efficient desulfurization performance in the catalytic oxidation of $\mathrm{H}_{2} \mathrm{~S}$, demonstrating its potential application for technological development in pollution control.

\section{Experimental section}

\subsection{Chemicals}

D-glucose, melamine, zinc chloride $\left(\mathrm{ZnCl}_{2}\right)$, potassium 
chloride $(\mathrm{KCl})$ and hydrochloric acid $(\mathrm{HCl}, 37 \mathrm{wt} \%)$ were purchased from Tianjin Kermel Chemical Reagent Co. Ltd. (Tianjin, China). All chemicals were analytical reagents.

\subsection{Preparation of NPCs}

The NPCs were prepared using melamine and D-glucose as precursors, and $\mathrm{KCl}-\mathrm{ZnCl}_{2}$ (3.6/6.4 by weight) as eutectic salt mixture (Scheme 1). In a typical process, $0.50 \mathrm{~g}$ melamine and $0.50 \mathrm{~g}$ D-glucose were ground with a mortar. Subsequently, $10.0 \mathrm{~g}$ pre-homogenized eutectics were added to powder mixture and milled for $5 \mathrm{~min}$. The mixture was heated to $700^{\circ} \mathrm{C}$ at $5^{\circ} \mathrm{C} / \mathrm{min}$ and kept for $5 \mathrm{~h}$ in a nitrogen flow. And $0.22 \mathrm{~g}$ product was obtained by washing with $\mathrm{HCl}(1 \mathrm{~mol} / \mathrm{L})$ and deionized water, followed by filtrating and drying at $120^{\circ} \mathrm{C}$. The weight ratio of salts to precursors is 10 , whereas the weight ratio of melamine to D-glucose (denoted as $M / G$ ) was varied from 0 to 2.0. $(M / G=0$ means only $D$-glucose is added into the precursor.)

In addition, NPCs were also prepared at different temperatures with fixed $M / G(1.0)$ and weight ratio (10) of salts to precursors. The homogeneous mixture of precursors and salts was heated to targeted temperature $(550,700$, 850 and $1000^{\circ} \mathrm{C}$ ) at $5^{\circ} \mathrm{C} / \mathrm{min}$ and kept $5 \mathrm{~h}$ in a $\mathrm{N}_{2}$ flow. The product was washed with $\mathrm{HCl}(1 \mathrm{~mol} / \mathrm{L})$ and deionized water, followed by filtrating and drying at $120^{\circ} \mathrm{C}$. The products were labelled as NPC- $x-y$, where $x$ represents ratio of $M / G(0,0.25,0.5,1.0$ and 2.0) and $y$ stands for the pyrolysis temperature $\left(550,700,850\right.$ and $\left.1000^{\circ} \mathrm{C}\right)$.

\subsection{Test of catalytic performance of NPCs}

In a typical process, $0.10 \mathrm{~g}$ NPC was packed in a quartz tube. A humidified (relative humidity $70 \%$ ) nitrogen flow containing $1000 \times 10^{-6} \mathrm{H}_{2} \mathrm{~S}$ and $2 \% \mathrm{O}_{2}$ were passed through the sample at a flow rate of $100 \mathrm{~mL} / \mathrm{min}$. The temperature was set at $20^{\circ} \mathrm{C}$ (controlled by a thermotank). Furthermore, NPC- $x-y$ was successively tested under the same condition.

In all of the tests, the $\mathrm{H}_{2} \mathrm{~S}$ concentrations in the exhaust gases from the quartz reactor were monitored using GC-7900 II gas chromatograph (produced by Shanghai Techcomp Bio-equipment Ltd.) equipped with a Porapak

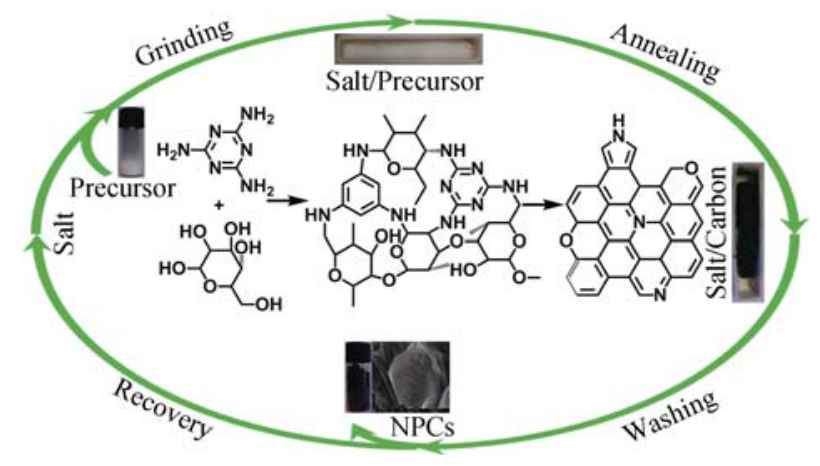

Scheme 1 Illustration of the synthetic process for NPCs
Q column and a flame photometric detector (FPD) (detection limit: $\left.1 \times 10^{-6}\right)$. The test was stopped at the point that the elution concentration $(C)$ was approximately equal to the inlet concentration $\left(C_{0}\right)$. The sulfur capacity $(Q)$ was calculated by using the following equation:

$$
Q_{t}=\frac{C_{0} P F}{1000 m R T} \int_{0}^{t}\left(1-\frac{C}{C_{0}}\right)
$$

Where $t$ is the reaction time ( $\mathrm{min}), F$ is the flow rate $(\mathrm{mL} / \mathrm{min}), P$ is sorption pressure $(\mathrm{Pa}), m$ is the weight of sorbent $(\mathrm{g}), T$ is the reaction temperature $\left({ }^{\circ} \mathrm{C}\right), R$ is ideal gas constant, $C_{0}$ and $C$ are the inlet and outlet concentration of $\mathrm{H}_{2} \mathrm{~S}\left(\times 10^{-6}\right)$, respectively.

\subsection{Characterization}

Nitrogen adsorption isotherms were measured at $77 \mathrm{~K}$ on a Micromeritics ASAP 2020 volumetric adsorption analyzer. The pore size was determined according to the non-local density functional theory method. The morphology and structures of the as-prepared products were observed using field emission scanning electron microscope (FESEM, NOVA NanoSEM 450). The weight percentages of $\mathrm{C}, \mathrm{H}$ and $\mathrm{N}$ in the NPCs were determined by Elemental Analyzer (Vario EL III). The chemical composition was analyzed by $\mathrm{X}$-rays photoelectron spectroscopy with $\mathrm{Al} \mathrm{K} \alpha \mathrm{X}$-rays radiation (XPS, Thermo ESCALAB250). The X-ray diffraction (XRD) patterns were acquired on a D/MAX-2400 diffractometer. The thermogravimetric analysis (TGA) was conducted on TG instrument (Shimadzu, DRG-60) in a nitrogen flow with a temperature ramp of $10^{\circ} \mathrm{C} / \mathrm{min}$.

\section{Results and discussion}

\subsection{Structure and textural properties of NPCs}

The sample displays sheet-like structure with tens of micrometer (Fig. 1(a) and (b)), and the sheet thickness of NPC-1.0-700 is $\sim 85 \mathrm{~nm}$ (Fig. 1(c)). Presumably, due to the rather unusual high polar characteristic, molten salt can dissolve polar intermediates derived from melamine and D-glucose, providing secondary growth environment for the nanosheets ${ }^{[14]}$. A representative elemental mapping (Fig. 1(e)-(g)) of one nanosheet (Fig. 1(d)) indicates the homogeneous distribution of $\mathrm{C}, \mathrm{N}$ and $\mathrm{O}$ element.

The pore structure for NPCs was analyzed by $\mathrm{N}_{2}$ adsorption, shown in Fig. 2 and summarized in Table 1. As seen in Fig. 2(a) and 2(c), the isotherms for all NPCs are of Type I, demonstrating microporous characteristics of these samples. The pore size distributions (Fig. 2(b) and 2(d)) indicate the surface area of NPCs is mainly contributed by micropores. In addition, one can see in Table 1 that when the carbonization temperature was fixed at $700^{\circ} \mathrm{C}$, increasing the weight ratio of nitrogen/carbon source $(M / G)$ from 0 to 1.0 led to 
increased specific surface area. In detail, the $S_{\mathrm{BET}}$ value increases from $645 \mathrm{~m}^{2} / \mathrm{g}$ for NPC-0-700 to $1355 \mathrm{~m}^{2} / \mathrm{g}$ for NPC-1.0-700. Higher $M / G$ means higher nitrogen in the precursor, and more nitrogen species would be released during the carbonization process, resulting in larger surface area. However, increasing $M / G$ from 1.0 to 2.0 gives rise to decreased surface area of NPC-2.0-700 $\left(1229 \mathrm{~m}^{2} / \mathrm{g}\right)$, which may result from the collapse of the micropores due to excess loss of carbon skeleton, indicated by the decreased micropore volume $\left(0.376\right.$ and $0.267 \mathrm{~cm}^{3} / \mathrm{g}$ for NPC-1.0-700 and NPC-2.0- 700, respectively).
When $M / G$ was allocated as 1.0 , elevating the carbonization temperature from $550^{\circ} \mathrm{C}$ to $1000^{\circ} \mathrm{C}$ causes successive increase of the surface area (1201 and $1416 \mathrm{~m}^{2} / \mathrm{g}$ for NPC-1.0-500 and NPC-1.0-1000) because of the continuous loss of nitrogen, oxygen and hydrogen species at high temperature (Table 2). It is worthy to noting that the BET surface area of the sample is only $15 \mathrm{~m}^{2} / \mathrm{g}$ when the mixture of D-glucose and melamine $(M / G=0.5)$ was carbonized at $700^{\circ} \mathrm{C}$ in the absence of $\mathrm{KCl}-\mathrm{ZnCl}_{2}$, indicating the crucial role of salts for the developed porosity of NPCs.
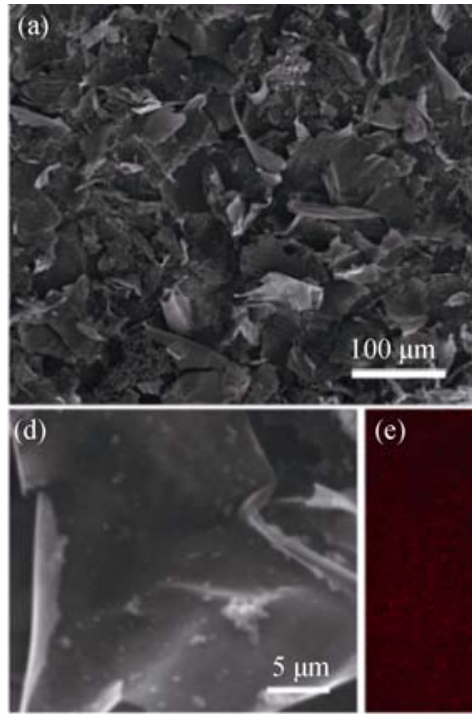
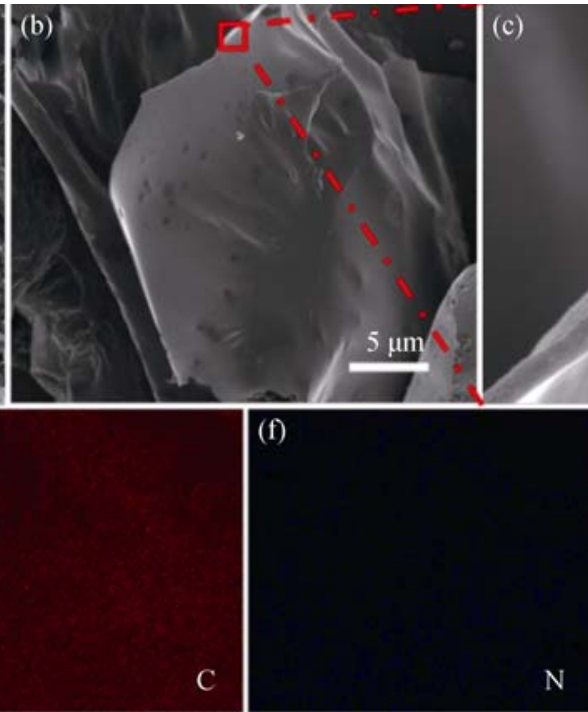

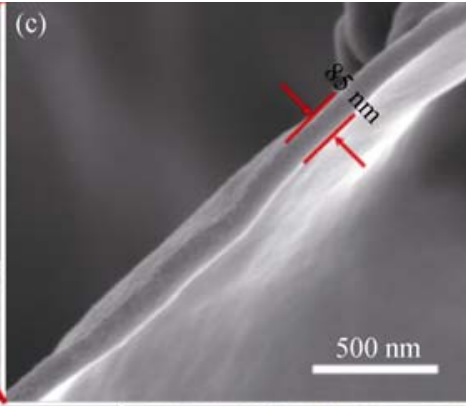

(g)

Fig. 1 (a-d) FESEM images of NPC-1.0-700, and c (e), N (f) and O (g) elemental mapping images of (d)
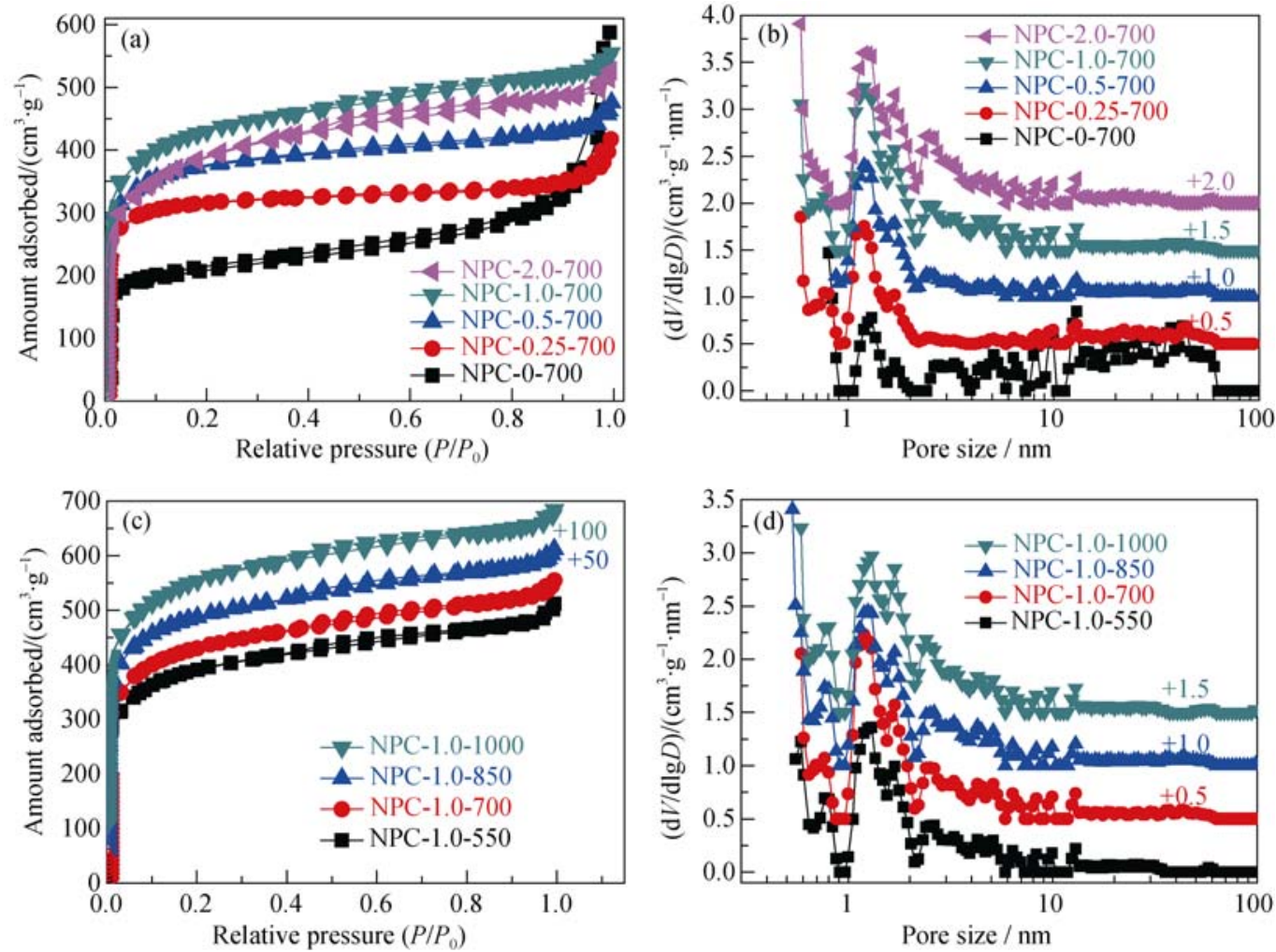

Fig. 2 Nitrogen adsorption isotherms $(a, c)$ and pore size distribution curves $(b, d)$ for NPCs 
Table 1 Pore structure of NPCs

\begin{tabular}{cccc}
\hline Sample & $\begin{array}{c}S_{\mathrm{BET}}{ }^{\mathrm{a}} / \\
\left(\mathrm{m}^{2} \cdot \mathrm{g}^{-1}\right)\end{array}$ & $\begin{array}{c}V_{\mathrm{tot}}{ }^{\mathrm{b}} / \\
\left(\mathrm{cm}^{3} \cdot \mathrm{g}^{-1}\right)\end{array}$ & $\begin{array}{c}V_{\text {mic }}{ }^{\mathrm{c}} / \\
\left(\mathrm{cm}^{3} \cdot \mathrm{g}^{-1}\right)\end{array}$ \\
\hline NPC-0-700 & 645 & 0.909 & 0.146 \\
NPC-0.25-700 & 927 & 0.645 & 0.296 \\
NPC-0.5-700 & 1129 & 0.736 & 0.271 \\
NPC-1.0-700 & 1355 & 0.858 & 0.419 \\
NPC-2.0-700 & 1229 & 0.814 & 0.393 \\
NPC-1.0-550 & 1201 & 0.792 & 0.414 \\
NPC-1.0-850 & 1383 & 0.869 & 0.478 \\
NPC-1.0-1000 & 1416 & 0.904 & 0.445 \\
\hline${ }^{a}$ BET surface area, ${ }^{\mathrm{b}}$ total pore volume,${ }^{\mathrm{c}}$ micropore volume
\end{tabular}

\subsection{Chemical compositions of NPCs}

As presented in Table 2, nitrogen content in NPCs can be tuned over a wide range by varying the carbonization temperature ( $\mathrm{N}$ content: $3.34 \mathrm{wt} \%-26.06 \mathrm{wt} \%$ ) or $M / G$ in the precursors ( $\mathrm{N}$ content: $0-23.98 \mathrm{wt} \%$ ). The carbonization temperature has great influence on the nitrogen doping level in NPCs. For the same precursor composition, elevating carbonization temperature leads to decreased nitrogen content, decreasing from $26.06 \mathrm{wt} \%$ for NPC-1.0-550 to $3.34 \mathrm{wt} \%$ for NPC-1.0-1000. In addition to the relative high nitrogen content $(20.73 \mathrm{wt} \%)$, NPC-1.0-700 shows relative high surface area $\left(1355 \mathrm{~m}^{2} / \mathrm{g}\right)$. Taking into the combination of high nitrogen content and high specific surface areas, $700^{\circ} \mathrm{C}$ was used as the typical carbonization temperature.

When the carbonization temperature is fixed at $700^{\circ} \mathrm{C}$, high amount of melamine in the precursors results in high nitrogen content of $23.98 \mathrm{wt} \%$ in NPC-2.0-700. Even at low $M / G$ of 0.25 , the nitrogen content in NPC-0.25-700 is as high as $11.88 \mathrm{wt} \%$, displaying the success synthesis of porous carbons with high nitrogen doping level. The high nitrogen content in NPCs is in favour of $\mathrm{H}_{2} \mathrm{~S}$ catalytic

Table 2 Chemical compositions of NPCs

\begin{tabular}{ccccc}
\hline Sample & $\mathrm{C} / \mathrm{wt} \%$ & $\mathrm{H} / \mathrm{wt} \%$ & $\mathrm{O}^{a} / \mathrm{wt} \%$ & $\mathrm{~N} / \mathrm{wt} \%$ \\
\hline NPC-0-700 & 91.67 & 0.073 & 8.26 & 0 \\
NPC-0.25-700 & 77.70 & 0.820 & 9.60 & 11.88 \\
NPC-0.5-700 & 73.32 & 1.060 & 9.55 & 16.07 \\
NPC-1.0-700 & 63.89 & 1.340 & 14.04 & 20.73 \\
NPC-2.0-700 & 55.47 & 2.120 & 18.43 & 23.98 \\
NPC-1.0-550 & 57.14 & 2.220 & 14.58 & 26.06 \\
NPC-1.0-850 & 75.59 & 0.940 & 13.48 & 9.99 \\
NPC-1.0-1000 & 87.04 & 0.360 & 9.26 & 3.34 \\
\hline${ }^{a}$ By difference & & & &
\end{tabular}

oxidation process. On the one hand, nitrogen functional groups in NPCs would improve the surface hydrophilicity of $\mathrm{NPCs}^{[15]}$, promoting the formation of water film on NPCs surface. On the other hand, nitrogen species in NPCs provide basic sites for dissociating $\mathrm{H}_{2} \mathrm{~S}$ molecules to $\mathrm{HS}^{-}$ions which are subsequently oxidized to elemental sulfur $^{[16]}$.

XPS was conducted to investigate the elemental composition and N-bonding configurations on the surface of NPCs. As can be seen in Fig. 3(a) and 3(c), nitrogen element can be detected in the survey scans in NPCs when melamine was introduced into the precursors. The high resolution N1s spectra for NPCs (Fig. 3(b) and 3(d)) were fitted with three peaks with peaks at about 398.2, 400.3 and $401.3 \mathrm{eV}$, corresponding to pyridinic, pyrrolic and graphitic nitrogen ${ }^{[17-20]}$, respectively. At the same pyrolysis temperature of $700^{\circ} \mathrm{C}$, the nitrogen configurations in porous carbons are pyrrolic and pyridinic (Fig. 3(b)), regardless of $M / G$ in the precursor. At lower pyrolysis temperature of $550^{\circ} \mathrm{C}$ and $700^{\circ} \mathrm{C}$, the nitrogen forms are pyridinic and pyrrolic $\mathrm{N}$, while graphitic N-bonding configuration is found at $850^{\circ} \mathrm{C}$ and $1000^{\circ} \mathrm{C}$ (Fig. 3(d)).

\subsection{Catalytic performance of NPCs}

The catalytic performance of NPCs was examined in a packed-bed reactor at $20^{\circ} \mathrm{C}$ under atmospheric pressure. The catalytic performance of NPCs was shown in Fig. 4. As for the sample prepared at $700^{\circ} \mathrm{C}$, NPC-0-700 without nitrogen doping has negligible sulfur capacity of $0.0213 \mathrm{~g} / \mathrm{g}$, whereas remarkably increased sulfur capacity can be achieved with the increase of $M / G$ from 0 to 1.0. Meanwhile, NPC-1.0-700 $(1.10 \mathrm{~g} / \mathrm{g})$ shows better catalytic performance than NPC-2.0-700 (0.93 g/g). Though NPC2.0-700 possesses the highest nitrogen level of $23.98 \mathrm{wt} \%$, NPC-1.0-700 with $20.73 \mathrm{wt} \%$ nitrogen content exhibits the highest catalytic desulfurization capacity. This indicates that too high nitrogen content above the value of $20.73 \mathrm{wt} \%$ is not necessary for desulfurization. As a result, pore structure of NPCs becomes more critical for $\mathrm{H}_{2} \mathrm{~S}$ catalytic oxidation performance over metal-free carbon catalysts. The high sulfur capacity of NPC-1.0-700 is attributed to its high nitrogen of $20.73 \mathrm{wt} \%$, suitable nitrogen configurations (pyrrolic and pyridinic $\mathrm{N}$ functional groups) and developed porosity. The overall catalytic oxidation mechanism is demonstrated as vapor-liquidsolid reaction mechanism ${ }^{[6]}$. In the catalytic oxidation process, the formation of a thin water film on the surface of porous carbon is critical, which dissolves $\mathrm{H}_{2} \mathrm{~S}$ molecules. The nitrogen-containing groups increase both the hydrophilicity of the carbon surface and the basicity of the 
water film, therefore promoting the dissociation of $\mathrm{H}_{2} \mathrm{~S}$ molecules into $\mathrm{HS}^{-}$ions. In the present work, the extra high nitrogen content in NPCs ensures the high concentration of $\mathrm{HS}^{-}$ions. Meanwhile, $\mathrm{O}_{2}$ molecules are adsorbed by the carbon atoms next to pyridinic $\mathrm{N}^{[17]}$. The interaction between $\mathrm{HS}^{-}$ions and adsorbed oxygen molecules leads to the oxidation of $\mathrm{HS}^{-}$and the formation of elemental sulfur ${ }^{[6,11]}$

As for the samples prepared at different pyrolysis temperatures, NPC-1.0-700 shows superior catalytic performance $(1.10 \mathrm{~g} / \mathrm{g})$ to NPC-1.0-550 $(0.983 \mathrm{~g} / \mathrm{g})$, NPC-1.0-850 $(0.623 \mathrm{~g} / \mathrm{g})$ and NPC-1.0-1000 $(0.130 \mathrm{~g} / \mathrm{g})$ though NPC-1.0-700 doses not possess the most developed porosity ( $S_{\mathrm{BET}}, V_{\text {tot }}$ and $V_{\text {mic }}$ ) or the highest nitrogen functional groups (see Fig. 4(e) and Table 1-2), hinting the significant synergistic effect of surface chemistry and porosity in NPCs for their catalytic performance. Nitrogen sorption results (Fig. 2) indicated that the pore structure is very similar for the samples prepared at different temperatures. Thus, the comprehensive relationships between nitrogen doping level, pore structure and catalytic performance are considered for NPCs prepared at different temperatures. The relationship between nitrogen content and $Q / S_{\mathrm{BET}}$ demonstrates a linear relationship $\left(R^{2}=0.9000\right)$ (Fig. 4(f)), giving an indicator that the sulfur capacity de-
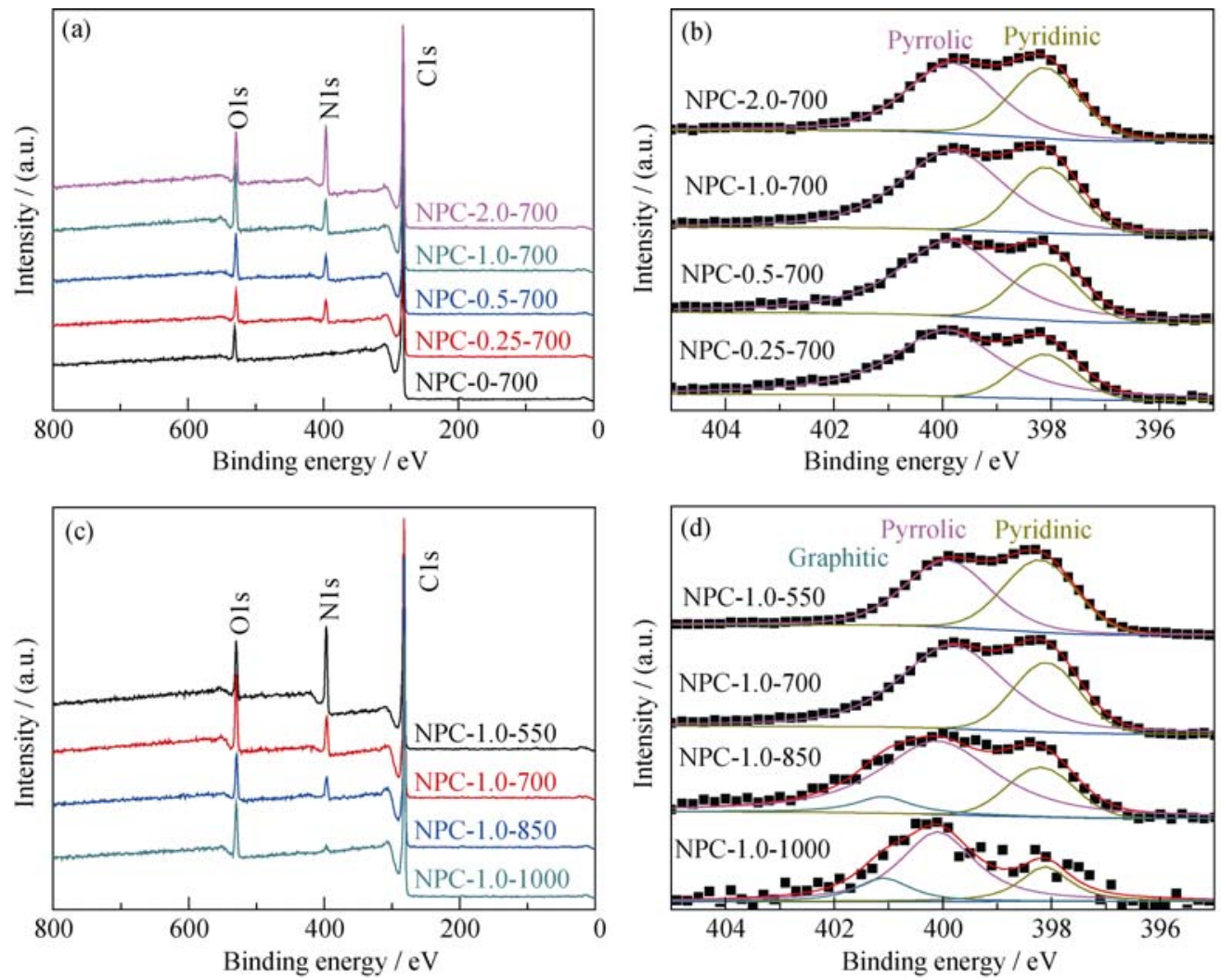

pends on the nitrogen content and surface area when the pore structure is similar.

\section{$2.4 \mathrm{H}_{2} \mathrm{~S}$ oxidation product over the NPCs}

NPC-1.0-700 was taken as an example. Compared with the fresh NPCs, XRD analysis (Fig. 5(a)) discloses weak intensity peaks corresponding to the polysulfides, suggesting that the initial state of sulfur should be in the form of an ultrathin $\mathrm{S}_{8}$ cluster (JCPDS 08-0247), in other words, amorphous sulfur. The elemental sulfur content in exhausted NPC-1.0-700 was determined by TGA in $\mathrm{N}_{2}$ (Fig. 5(b)). The weight loss between $150^{\circ} \mathrm{C}$ and $380^{\circ} \mathrm{C}$ should be assigned to the removal of elemental sulfur from the micropores of the spent NPC-1.0-700 $0^{[6,8]}$. At the temperature of $380^{\circ} \mathrm{C}$, the weight loss difference between fresh and exhausted NPC-1.0-700 is $50.6 \%$, corresponding to the sulfur content of $1.02 \mathrm{~g} / \mathrm{g}$, and the calculated sulfur capacity by TGA is $1.08 \mathrm{~g} / \mathrm{g}$, well consistent with the sulfur capacity calculated from the breakthrough curves $(1.10 \mathrm{~g} / \mathrm{g})$. The morphology of the exhausted catalyst was observed by FESEM (Fig. 5(c)). It can be seen the spent sample is also sheet-like, similar to the fresh one (Fig. 1(b)). The nitrogen and sulfur elemental mapping (Fig. 5(d) and 5(e)) demonstrates that $\mathrm{N}$ and $\mathrm{S}$ elements are evenly distributed in the carbon sheet.

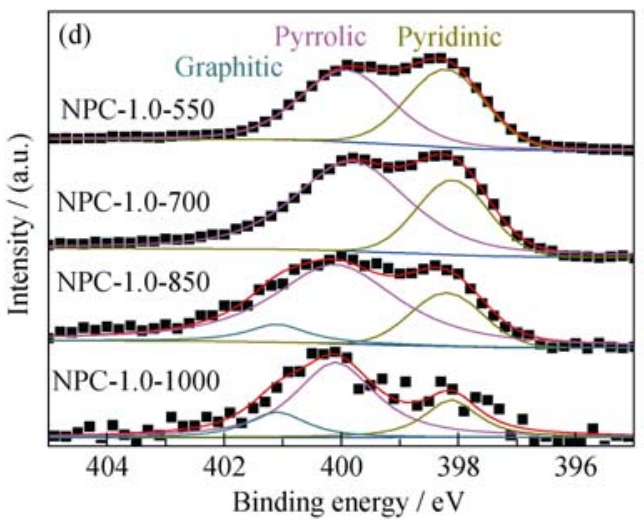

Fig. 3 XPS survey (a, c) and high-resolution N1s spectra (b, d) of NPCs 

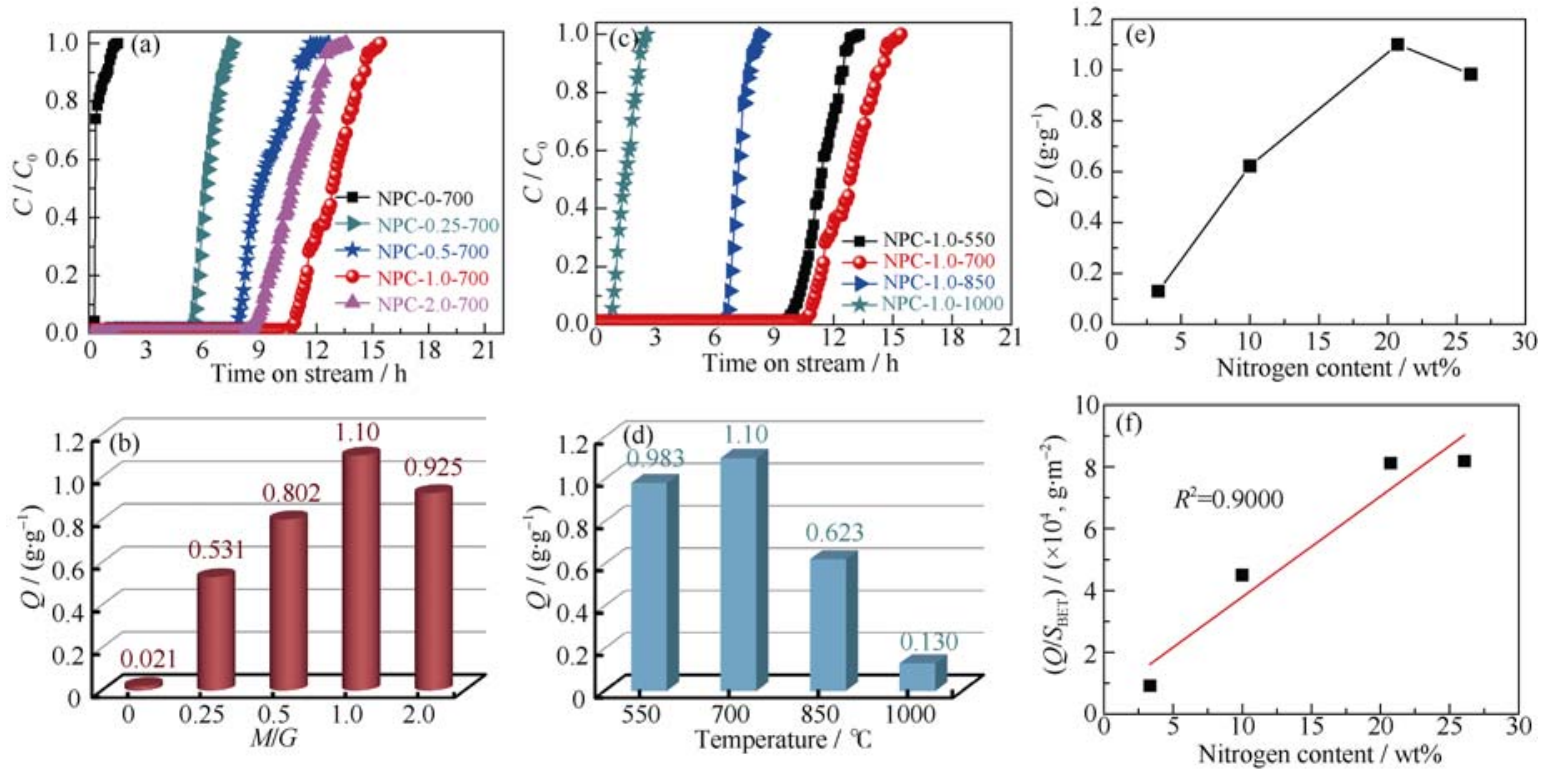

Fig. 4 (a, c) $\mathrm{H}_{2} \mathrm{~S}$ breakthrough curves, (b, d) sulfur capacities of NPCs, (e, f) the relationship between sulfur capacities and nitrogen content, porosity
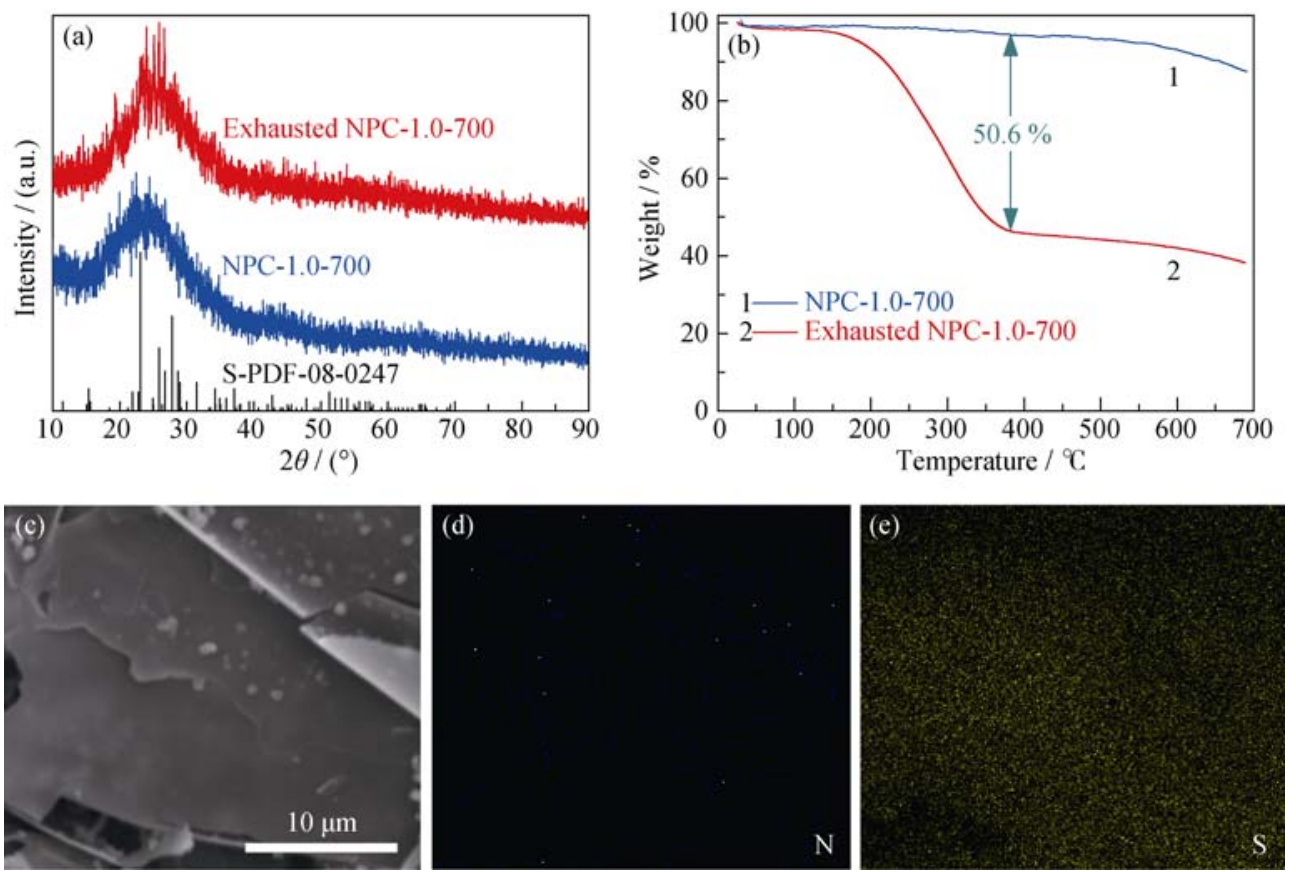

Fig. 5 (a) XRD patterns and (b) TGA curves in $\mathrm{N}_{2}$ of fresh and exhausted NPC-1.0-700 sample. (c) FESEM image of the exhausted NPC-1.0-700. The elemental N (a) and S (e) mapping images of (c)

\section{Conclusions}

In summary, we present a facile salt melt route for the preparation of $\mathrm{N}$-doped porous carbons with different porous structures and nitrogen contents. When used as metal-free catalysts for $\mathrm{H}_{2} \mathrm{~S}$ oxidation to elemental sulfur, high sulfur capacity can be achieved due to the notably high nitrogen basic sites concentration, developed porosity $\left(S_{\mathrm{BET}}>1300 \mathrm{~m}^{2} / \mathrm{g}\right)$ and appropriate nitrogen configuration (pyrrolic and pyridinic N). The cost-effective synthesis is convenient and eco-friendly, making N-doped porous carbons inexpensive production for industrial $\mathrm{H}_{2} \mathrm{~S}$ removal.

\section{References:}

[1] JIANG L, ZHU H-W, RAZZAQ R, et al. Effect of zirconium addition on the structure and properties of $\mathrm{CuO} / \mathrm{CeO}_{2}$ catalysts for high-temperature wateregas shift in an IGCC system. Int. J. Hydrogen Energy, 2012, 37(21): 15914-15924.

[2] MOIOLI S, PELleGRINI L A, PICUTTI B, et al. Improved 
rate-based modeling of $\mathrm{H}_{2} \mathrm{~S}$ and $\mathrm{CO}_{2}$ removal by methyldiethanolamine scrubbing. Ind. Eng. Chem. Res., 2013, 52(5): 2056-2065

[3] PIÉPlu A, SAUR O, LAVAlLEY J C, et al. Claus catalysis and $\mathrm{H}_{2} \mathrm{~S}$ selective oxidation. Catal. Rev., 1998, 40(4): 409-450.

[4] DUAN H, YAN R, KOE L C, et al. Combined effect of adsorption and biodegradation of biological activated carbon on $\mathrm{H}_{2} \mathrm{~S}$ biotrickling filtration. Chemosphere, 2007, 66(9): 1684-1691.

[5] SEREDYCH M, BANDOSZ T J. Desulfurization of digester gas on catalytic carbonaceous adsorbents: complexity of interactions between the surface and components of the gaseous mixture. Ind. Eng. Chem. Res., 2006, 45(10): 3658-3665.

[6] SUN F G, LIU J, CHEN H C, et al. Nitrogen-rich mesoporous carbons: highly efficient, regenerable metal-free catalysts for low-temperature oxidation of $\mathrm{H}_{2} \mathrm{~S}$. ACS Catal., 2013, 3(5): 862-870.

[7] BANDOSZ T J. On the adsorption/oxidation of hydrogen sulfide on activated carbons at ambient temperatures. J. Colloid Interface Sci., 2002, 246(1): 1-20.

[8] CHEN Q J, WANG Z, LONG D H, et al. Role of pore structure of activated carbon fibers in the catalytic oxidation of $\mathrm{H}_{2} \mathrm{~S}$. Ind. Eng. Chem. Res., 2010, 49(7): 3152-3159.

[9] ADIB F, BAGREEV A, BANDOSZ T J. Adsorption/oxidation of hydrogen sulfide on nitrogen-containing activated carbons. Langmuir, 2000, 16(4): 1980-1986.

[10] BAGREEV A, ANGEL MENENDEZ J, DUKHNO I, et al. Bituminous coal-based activated carbons modified with nitrogen as adsorbents of hydrogen sulfide. Carbon, 2004, 42(3): 469-476.
[11] BANDOSZ T J. Activated Carbon Surfaces in Environmental Remediation. New York: Academic Press, 2006: 231-292.

[12] FECHLER N, FELLINGER T P, ANTONIETTI M. "Salt templating": a simple and sustainable pathway toward highly porous functional carbons from ionic liquids. Adv. Mater., 2013, 25(1): 75-79.

[13] LIU X, FECHLER N, ANTONIETTI M. Salt melt synthesis of ceramics, semiconductors and carbon nanostructures. Chem. Soc. Rev., 2013, 42(21): 8237-8265.

[14] LIU X, GIORDANO C, ANTONIETTI M. A facile molten-salt route to graphene synthesis. Small, 2014, 10(1): 193-200.

[15] LAHAYE J, NANSE G, BAGREEV A, et al. Porous structure and surface chemistry of nitrogen containing carbons from polymers. Carbon, 1999, 37: 585-590.

[16] SEREDYCH M, BANDOSZ T J. Adsorption of hydrogen sulfide on graphite derived materials modified by incorporation of nitrogen. Mater. Chem. Phys., 2009, 113(2/3): 946-952.

[17] GUO D H, SHIBUYA R, AKIBA C, et al. Active sites of nitrogen-doped carbon materials for oxygen reduction reaction clarified using model catalysts. Science, 2016, 351(6271): 361-365.

[18] ZHONG-MIN W, YING-DE W, YONG-PENG L E I, et al. In-situ preparation and electrocatalytic oxygen reduction performance of N-doped graphene@CNF. J. Inorg. Mater., 2016, 31(4): 351.

[19] LI Z J, LV W, ZHANG C, et al. A sheet-like porous carbon for high-rate supercapacitors produced by the carbonization of an eggplant. Carbon, 2015, 92: 11-14.

[20] WANG C, ZHAN L, HUANG Z H, et al. Metal-catalyst-free growth and characterization of nitrogen-doped carbon nanotubes. $J$. Inorg. Mater., 2011, 26(8): 881-884.

\title{
熔盐法制备氮椮杂多孔炭及其催化脱硫性能
}

\author{
余正发，王旭珍，侯亚男，赵宗涁，李 荻，邱介山
}

(精细化工国家重点实验室暨辽宁省能源材料化工重点实验室, 大连理工大学, 化工与环境生命学部, 化学学院, 大连 116024)

摘 要: 采用熔融盐合成技术，以生物质葡萄糖和富氮三聚㲵胺为前驱体，成功制备得到具有发达孔隙结构(BET 表面 积: $1355 \mathrm{~m}^{2} / \mathrm{g}$ )和极高氮掺杂量 $(20.73 \mathrm{wt} \%)$ 的氮掺杂多孔炭材料。X 射线光电子能谱(XPS)分析表明，多孔炭材料中的 氮原子主要以吡咯及吡啶构型存在，这两种形态的氮原子有利于硫化氢的吸附及催化氧化。在常温、常压下，所制备 氮掺杂多孔炭对硫化氢非金属催化转化为单质硫的脱除硫容高达 $1.10 \mathrm{~g} / \mathrm{g}$ 。该合成方法简便易行，有望实现氮掺杂多 孔炭材料的批量和廉价制备，合成的氮掺杂多孔炭在污染物控制领域应用潜能巨大。

关 键 词: 氮掺杂多孔炭; 熔融盐合成技术; 硫化氢; 非金属催化

中图分类号: O613

文献标识码: A 